\title{
Pengaruh Proses Belajar Mengajar Yang Menggunakan Dan Tidak Menggunakan Alat Peraga
}

Beny Suyanto, Karno, Sujangi

\begin{abstract}
Water treatment props used in the learning process is intended to clarify the material presented lectures more interesting and easier to understand. How much influence the process of learning to use and not use props is a water treatment in this study.

Analytical study of the design of one group pretest-posttest conducted with a sample of Environmental Health Prodi third semester students during the academic year 2014/2015 in the month of September until November 2014.

Students of 51 people divided into two groups $A$ and group $B$ were based on the average value of the first semester GPA (a) and II (two) are intended to have the same ability level and evenly. Group learning process does not use props and group $B$ with the use of props water treatment.

The results of students' pre-test group $A$ and $B$ do not pass the value of the gain and the highest and lowest 50 20. While the results of a group of students posttest score average of 67.3, the lowest and highest value of 60.7 79.3. The student group B average value 78.3, the lowest value of 70, and the highest 84.7. There are significant differences utilize the learning process and not use props.

The above data indicate that the level of understanding of the students in the lecture using props are better than without props. Konfrehensif cognitive abilities and effective student group $B$ was also better. Props water treatment also allows professors to teach and improve communication skills for students. Thus, each subject-oriented knowledge and skills needed innovation of science and technology major props adequate.
\end{abstract}

\section{PENDAHULUAN}

Teaching or audiovisual aids merupakan alat yang digunakan Dosen ketika mengajar untuk membantu memperjelas materi kuliah yang disampaikan dan mencegah terjadinya verbalisme dan pengajaran akan lebih menarik bila Mahasiswa senang karena mereka merasa tertarik dan mengerti materi kuliah yang diterimanya. ( M. Uzer Usman, 2005).

Kopetensi kurikulum program studi kesehatan lingkungan utamanya mata kuliah keahlian berkarya (MKB) Penyediaan Air Bersih dan Pengelolaan Limbah (PAPLC) setelah melalui proses belajar mengajar (PBM ) mahasiswa diharapkan mampu merencanakan rancang bangun sistem pengolahan air dan pengelolaan limbah cair, operasinal dan mantenentnya.

Desain tech unit pengolahan air sebagai media belajar merupakan alternatif yang perlu dipertimbangkan dari sekian banyak pilihan proses pengolahan air bersih. Kendatipun dalam kapasitas kecil, dengan tersedianya maket ini akan menjadi media belajar dan berlatih Mahasiswa dalam proses perencanaan, operational dan mentenent, uji labolatarium, serta mampu mengembangkan inovasi ilmu pengetahuan dan teknologi (IPTEK).

Mengkondisikan unit proses pengolahan air bersih sesuai keadaan lapangan akan memberikan bekal yang berarti bagi mahasiswa maupun alumni Jurusan Studi Kesehatan lingkungan di tengah-tengah persaingan yang ketat dalam memperoleh pekerjaan. Dari latar belakang tersebut di atas perlu dilakukan penelitian tentang Pengaruh Proses Belajar Mengajar Yang Menggunakan Dan Tidak Menggunakan Alat Peraga Pengolahan Air bersih

Tujuan penelitian ini adalah Menganalisis perbedaan pengaruh proses belajar mengajar yang menggunakan dan tidak menggunakan alat peraga pengolahan air bersih.

\section{METODE PENELITIAN}

Desain penelitian ini mengunakan two group pre test - postest desain

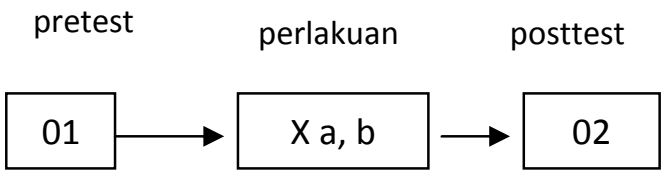


01 Tingkat kemampuan mahasiswa memahami materi pengolahan air bersih sebelum memperoleh PBM

X Perlakuan berupa proses belajar mengajar : pengolahan air bersih

a Perlakuan berupa proses belajar mengajar : pengolahan air bersih tanpa alat peraga

b Perlakuan berupa proses belajar mengajar : pengolahan air bersih tanpa alat peraga.

02 Hasil evaluasi PBM dengan alat peraga dan tidak menggunakan alat peraga (Suharyo Hadisaputro, 2000)

Populasi adalah mahasiswa program studi kesehatan lingkungan Magetan dan Sampel : Mahasiswa. semester III tahun akademi 2014/2015. Lokasi Penelitian di Program studi kesehatan lingkungan Magetan. Jl. Tri Pandita Magetan dilakukan selama 4 bulan. Analisis Data pengolahan data analisa table dan uji statistik $\mathrm{t}$ - test. Prosedur Penelitian

1. Menyiapkan buku Pedoman Pengolahan air : Pendahuluan: Konsep dasar perencanaan, Unit Intake, Unit pompa dan aerasi, Unit Prasedimentasi, Unit Flash Mixing, Unit Sedimentasi, Unit Filtrasi, Unit Koagulant, unit Desinfeksi.

2. Mendisain dimensi masing-masing unit pengolahan.

dengan perhitungan dengan formula kapasitas pengolahan kecil.
3. Merakit masing-masing unit pengolahan air (table 1): Semua unit dirakit dalam satu meja dengan memperhatikan beda tinggi dengan aliran gravitasi.

4. Melaksanakan proses belajar mengajar Mahasiswa 51 orang dibagi dalam group A dan group B yang didasarkan pada nilai indeks prestasi rata-rata semester I dan II dimaksudkanagar mempunyai tingkat kemampuan yang sama dan merata. Group A proses belajar mengajar tidak menggunakan alat peraga dilaksanakan di klas. sedangkan group B menggunakan alat peraga pengolahan air di workshop. air. Masing-masing kelompok memperoleh jam tatap muka $3 \times 100$ menit dan mahasiswa dibekali buku panduan yang sama.

5. Mengevaluasi PBM : Pretest dan posttest, baik group A maupun group B.

6. Menganalisa proses belajar mengajar yang menggunakan dan tidak menggunakan alat peraga pengolahan air.

7. Dari hasil evaluasi baik pre test maupun post test.

HASIL PENELITIAN DAN PEMBAHASAN

Hasil perhitungan dan dimensi alat pengolahan air adalah

Tabel 1. Rincian unit pengolahan air dan spesifikasi peralatan

\begin{tabular}{|c|c|c|}
\hline No & Unit & Spesifikasi \\
\hline 1 & Debit & $0,1 \mathrm{lt} / \mathrm{s}$ \\
\hline 2 & Unit Intake & $\begin{array}{l}\text { 1) Water cannal calm : panjang } 150 \mathrm{~cm} \text {; lebar } 10 \mathrm{~cm} \text {; dalam 2,2 cm; } \\
\text { warking } 11 \mathrm{~cm} \text {; 2). Grit chamber : panjang } 14 \mathrm{~cm} \text {; lebar } 20 \mathrm{~cm} \text {; } \\
\text { dalam } 1.1 \mathrm{~cm} \text {; warking } 11 \mathrm{~cm} ; 3) . \text { Pashall flume : 4). Sourge well : } \\
\text { panjang } 70 \mathrm{~cm} \text {; lebar } 10 \mathrm{~cm} \text {; dalam } 11 \mathrm{~cm} \text {; }\end{array}$ \\
\hline 3 & $\begin{array}{l}\text { Unit pompa } \\
\text { dan aerasi }\end{array}$ & $\begin{array}{l}\text { Unit pompa } \\
\text { Kapasitas mak : } 900 \mathrm{lt} / \mathrm{jam} ; \text { Daya pompa } 20 \text { watt ; Beda potensial : } \\
220 \mathrm{~V} \text {; Dischange heat : } 130 \text { mSuction heat : } 0 \mathrm{~m} \text {; Total heat : } 130 \\
\mathrm{~m} \text {;Presure switch water level : off } 0,15 \mathrm{~kg} / \mathrm{cm}^{2} \text { on } 0,1 \mathrm{~kg} / \mathrm{cm} ; \text { Pipe } \\
\text { size : } 0,95 \mathrm{~cm} \text {. } \\
\text { Unit Aerator } \\
\text { Panjang : lebar dan tinggi }=20 \times 20 \times 20 \mathrm{~cm}^{3} . ; \text { Free boat : } 3 \mathrm{~cm} ., \\
\text { Jumlah tray } 5 \text { buah; Sistem aerator multytray aerator }\end{array}$ \\
\hline 4 & $\begin{array}{l}\text { Unit } \\
\text { Prasedimentasi }\end{array}$ & $\begin{array}{l}\text { Jumlah } 3 \text { buah dengan ukuran masing-masing Panjang : } 80 \mathrm{~cm} \text {, lebar } \\
: 20 \mathrm{~cm} \text { lebar : } 26 \mathrm{~cm} \text {, Mesin Pencucian lumpur :Daya : } 20 \text { watt ;Beda } \\
\text { tegangan } 220 / 50 \mathrm{~Hz} \text {; Suctin heat : } 1,8 \mathrm{~m} \text {; Dischange heat : } 0 \mathrm{~m} \text {; } \\
\text { Pipe size jaringan : } 1 / 2 \text { ". ;Debit maks : } 900 \text { It/jam }\end{array}$ \\
\hline 5 & $\begin{array}{l}\text { Unit flash } \\
\text { mixing }\end{array}$ & $\begin{array}{l}\text { Jumlah } 2 \text { buah ;Dimensi bak : 7x7x10 } \mathrm{cm}^{3} ; \text { Putaran paddle : 2sd } 150 \\
\text { rpm }\end{array}$ \\
\hline 6 & $\begin{array}{l}\text { Unit } \\
\text { sedimentasi }\end{array}$ & $\begin{array}{l}\text { Jumlah } 3 \text { buah ; Dimensi : panjang : } 35 \mathrm{~cm} \text {; lebar } 20 \mathrm{~cm} \text { dan tinggi : } \\
16 \mathrm{~cm} \text {; freeboat : } 2 \mathrm{~cm}\end{array}$ \\
\hline 7 & Unit Filtrasi & $\begin{array}{l}\text { Jumlah } 4 \text { buah ; Dimensi : panjang : } 20 \mathrm{~cm} \text {; lebar } 20 \mathrm{~cm} \text { dan tinggi : } \\
18 \mathrm{~cm} \text {; freeboat : } 2 \mathrm{~cm}\end{array}$ \\
\hline
\end{tabular}




\begin{tabular}{c|l|l}
\hline No & \multicolumn{1}{|c|}{ Unit } & \multicolumn{1}{c}{ Spesifikasi } \\
\hline 8 & Bahan & Jumlah 1 buah ; Dimensi : $6 \mathrm{It} / \mathrm{hr} ;$ Debit : 0,07 ml/s ; Tawas : 0,378 \\
& koagulant & $\mathrm{kg} / \mathrm{hr} ;$ Air : 5,4 It/hr \\
\hline 9 & Desinfeksi & $\begin{array}{l}\text { Jumlah } 1 \mathrm{buah} ; \text { Dimensi : 0,3 lt/hr; Debit : 0,21 ml/mnt ; kaporit : } \\
0,03 \mathrm{~kg} / \mathrm{hr} ; \text { Air : 0,27 It/hr }\end{array}$ \\
\hline
\end{tabular}

Tabel 2

Rekapitulasi Hasil pre test dan Post test mahasiswa group A dan B

\begin{tabular}{|c|c|c|c|c|c|}
\hline \multicolumn{3}{|c|}{$\begin{array}{l}\text { Hasil pre test dan post test } \\
\text { mahasiswaa Group A }\end{array}$} & \multicolumn{3}{|c|}{ Hasil pre test dan post test mahasiswaa Group B } \\
\hline $\begin{array}{l}\text { Nomer } \\
\text { sampel }\end{array}$ & $\begin{array}{c}\text { Hasil } \\
\text { pre test }\end{array}$ & $\begin{array}{l}\text { Hasil Post } \\
\text { test }\end{array}$ & Nomer sampel & Hasil pre test & Hasil Post test \\
\hline$A$ & $B$ & $C$ & $D$ & $E$ & $F$ \\
\hline 1 & 40 & 78.7 & 27 & 30 & 84.0 \\
\hline 2 & 40 & 78.0 & 28 & 30 & 73.3 \\
\hline 3 & 35 & 68.0 & 29 & 40 & 82.7 \\
\hline 4 & 35 & 66.7 & 30 & 30 & 70.7 \\
\hline 5 & 35 & 66.0 & 31 & 40 & 84.0 \\
\hline 6 & 40 & 62.0 & 32 & 30 & 78.0 \\
\hline 7 & 50 & 61.3 & 33 & 30 & 78.7 \\
\hline 8 & 40 & 59.3 & 34 & 30 & 64.7 \\
\hline 9 & 30 & 70.0 & 35 & 40 & 80.0 \\
\hline 10 & 30 & 64.0 & 36 & 30 & 82.7 \\
\hline 11 & 30 & 64.0 & 37 & 40 & 82.7 \\
\hline 12 & 30 & 70.0 & 38 & 20 & 74.7 \\
\hline 13 & 40 & 66.0 & 39 & 20 & 82.0 \\
\hline 14 & 40 & 79.3 & 40 & 30 & 82.7 \\
\hline 15 & 40 & 62.7 & 41 & 30 & 84.7 \\
\hline 16 & 40 & 63.3 & 42 & 40 & 86.7 \\
\hline 17 & 30 & 66.0 & 43 & 30 & 75.3 \\
\hline 18 & 20 & 66.7 & 44 & 30 & 78.7 \\
\hline 19 & 30 & 66.0 & 45 & 40 & 81.3 \\
\hline 20 & 20 & 68.7 & 46 & 30 & 79.3 \\
\hline 21 & 30 & 66.7 & 47 & 20 & 77.3 \\
\hline 22 & 30 & 60.7 & 48 & 30 & 77.3 \\
\hline 23 & 40 & 73.3 & 49 & 30 & 75.3 \\
\hline 24 & 30 & 67.3 & 50 & 30 & 70.0 \\
\hline 25 & 30 & 64.0 & 51 & 30 & 72.0 \\
\hline 26 & 30 & 70.0 & 52 & - & - \\
\hline Rerata & 34,0 & 67,3 & Rerata & 31,2 & 78.3 \\
\hline
\end{tabular}

Data primer : hasil evaluasi pretest dan posttest

a. Tingkat pemahaman mahasiswa group $\mathrm{A}$ dan B

1. Hasil penilaian jenis soal kelompok 1 (satu)

Tingkat pemahaman mahasiswa group $B$ lebih baik dibanding dengan group $\mathrm{A}$. Hal dapat dikaji dari hasil nilai rata-rata mahasiswa group B : 82,4 berada di level lambang mutu $A$ dan mahasiswa group $A$ : 77,7 berada pada level $B$.

2. Hasil penilaian jenis soal kelompok 2 (dua).

Jenis soal kelompok 2 (dua) mempunyai bobot 2 (dua) mempunyai kesulitan lebih tinggi daripada jenis soal kelompok 1 (satu). Hasil penilaian mahasiswa group
A rata-rata :62 dan group : 76. Hal ini dapat disimpulkan bahwa dengan penggunaan alat peraga dalam proses belajar mengajar (PBM) menunjukan pamahaman kognitif dan afektif mahasiswa lebih baik. Penggunaan alat peraga mendorong mahasiswa berinisiatif untuk melakukan seperti diskusi, analisis dan evaluasi (slameto,2000)

3. Hasil rekapitulasi jenis soal kelompok 1 (satu) dan 2 (dua).

Hasil akhir dari kegiatan post test adalah hasil rekapitulasi jenis soal kelompok satu yang berbobot satu dan jenis soal kelompok dua yang berbobot dua. Mahasiswa group A menunjukan nilai 
rata-rata :67,3 dan mahasiswa group $B$ : 78,3. Hal ini menunjukan bahwa tingkat pemahaman mahasiswa dalam perkuliahan menggunakan alat peraga hasil post testnya lebih baik dibanding tanpa alat peraga. Tingkat ketrampilannya juga lebih baik.

Kemampuan konfrehensif dari kognitif dan efektif mahasiswa group B ternyata juga lebih baik. Dengan tersedianya alat peraga pengolahan air ini juga memudahkan dosen dalam mengajar dan meningkatkan pemahaman bagi mahasiswa. Jumlah jam tatap muka juga lebih efisien. Alat peraga membuktikan memperbesar perhatian mahasiswa dan memberi pengalaman yang nyata yang dapat menumbuhkan kegiatan berusaha sendiri di kalangan mahasiswa (Mujiono,2006).

Alat peraga pengolahan air yang digunakan ini mampu menambah kemampuan komunikasi, memungkinkan belajar lebih baik karena adanya hubungan unit-unit pengolahan yang tersedia (Hasibuan, 2007).

4. Dari hasil uji T test menunjukkan bahwa $p=0,00$, dimana $p \leq 0,05$, maka Ho ditolak artinya ada perbedaan nilai post test antara proses Belajar Mengajar (PBM) yang menggunakan alat peraga dan PBM yang tidak menggunakan alat peraga pengolahan air

\section{KESIMPULAN}

1. Proses belajar mengajar dilakukan menggunakan alat peraga pengolahan air ternyata mampu membantu melatih pola pikir mahasiswa agar dapat memecahkan masalah dengan kritis, logis, cermat dan tepat guna.

2. Alat peraga lebih mudah memberikan pemahaman mahasiswa, memperbesar perhatian dan meningkatkan komunikasi mahasiswa dalam kegiatan belajar.

3. Hasil evaluasi belajar menggunakan alat peraga pengolahan air diperoleh nilai rata-rata 78,3 dan tidak menggunakan alat peraga 67,3 . Ada perbedaan yang signifikan nilai hasil belajar antara PBM menggunakan alat peraga dan tidak menggunakan alat peraga.

\section{SARAN}

1. Untuk meningkatkan kemampuan mahasiswa baik aspek pengetahuan dan ketrampilan diperlukan alat peraga inovasi baru yang mengacu pada iptek.

2. Dalam mewujudkan alat peraga, akan lebih baik jika mahasiswa diikutkan dalam perencanaan dan pembuatannya. Hal ini dimaksudkan agar mahasiswa lebih mudah memahami dan mempunyai ketrampilan di bidang kuliah yang dipelajari.

3. Perlu diciptakan alat peraga yang berkaitan dengan mata kuliah yang memerlukan tingkat pemahaman aspek pengetahuan dan ketrampilan.

\section{DAFTAR PUSTAKA}

Bowo D M., 1999. Hydrolika teknik Penyehatan dan Lingkungan, ITS Surabaya.

Dep.PU, 1999. Advance Course Mechanical Installation, Dirjen Cipta Karya, Jakarta.

Djoko sasongko, 2000. Teknik sumber daya air , Erlangga, Jakarta.

Hasibuan, 2007. Proses belajar mengajar. Remaja Karya, Jakarta

M. User Usman, 2005. Menjadi guru profesional. Remaja Rosdakarya, Bandung.

Nur Yuwono, 1999. Hydrolika. Hanindita, Yogyakarta.

Saufyan dan Morimura, 2002. Perancangan dan pemeliharaan sistem plumbing, Pradnya paramita, Jakarta.

Srimulyani, 2010. Pembelajaran matematika dengan alat peraga papan berpasangan, E-jurnal Dinas Pendidikan Kota Surabaya, Surabaya

Suharyo Hadisaputro, Prof 2000. Tipologi dan rancangan penelitian, Undip, Semarang 